\title{
A Symptomatic Displaced Os Odontoideum: A Case Report
}

\author{
Farshad Nikouei, ${ }^{1}$ Khodakaram Rastegar, ${ }^{1}$ Ali Andalib, ${ }^{1}$ and Saeed Sabbaghan ${ }^{1, *}$ \\ ${ }^{1}$ Bone and Joint Reconstruction Research Center, Shafa Orthopedic Hospital, Iran University of Medical Sciences, Tehran, IR Iran \\ "Corresponding author: Saeed Sabbaghan, Bone and Joint Reconstruction Research Center, Shafa Orthopedic Hospital, Iran University of Medical Sciences, Tehran, IR Iran. Tel: \\ +98-2133542020, Fax: +98-2133542010, E-mail: saeed.sabbaghan@gmail.com
}

Received 2015 December 03; Revised 2016 April 09; Accepted 2016 April 15.

\begin{abstract}
Introduction: Os odontoideum $(\mathrm{OO})$ is a form of odontoid anomaly presented by a separate ossicle with a smooth, sclerotic border not fused with $\mathrm{C} 2$ body. The current paper reports a boy with irreducible displaced os odontoideum with severe neurologic deficit after a minor trauma.

Case Presentation: A16-year-old boy admitted in the center due to neck pain and torticollis with neurologic deficit. He had a history of multiple minor traumas. Advanced imaging assessment demonstrated displaced os odontoideum with minimal space available for cord (SAC) and myelomalacia. After unsuccessful closed reduction a 2-stage operation was planned: first, the anterior transoral release and odontoid resection with subsequent halo-traction and second, the posterior atlanto-axial instrumented fusion with bilateral $\mathrm{C} 1$ hook and $\mathrm{C} 2$ pedicular screws.

Conclusions: Congenital anomalies of the odontoid are associated with C1-C2 instability that can be subluxated or dislocated with minor trauma and cause permanent neurologic deficit or even death. When acute cervical spine trauma is imaged, os odontoideum should be distinguished from an acute dens fracture with a multimodality imaging approach including computed tomography (CT), magnetic resonance imaging (MRI) and radiography. Here is the report of a rare case with irreducible displaced os odontiodeum treated him with anterior release, odontoid resection and posterior C1-C2 instrumented fusion.
\end{abstract}

Keywords: Os Odontoideum, Myelopathy, Odontoidectomy

\section{Introduction}

Os odontoideum (OO) is a form of odontoid anomaly; other forms of this anomaly are aplasia and hypoplasia (1). The os odontoideum is a separate bone with smooth, rounded cortical margins, usually about half the size of the odontoid process. The gap between the os odontoideum and the second cervical vertebra (the axis) is wide and lies above the level of its superior facet (2). Since this lesion is frequently asymptomatic and remains undiscovered until it is brought to the physician's attention by trauma or the onset of symptoms, the exact incidence of os odontoideum is unknown, but it is probably more common than estimated. Minor trauma can cause rapid deterioration of neurological function in asymptomatic patient with danger of serious consequences and even death (3). It is reported that odontoid anomalies are more common in patients with Down syndrome, Klippel-Feil syndrome, Morquio syndrome and spondyloepiphyseal dysplasia (1).

The odontoid process projects superiorly from the body of the axis and begins to ossify between the first and fifth months of prenatal life. Its tip arises embryologically from the fourth occipital sclerotome along with the occipital condyles and the rim of the foramen magnum (4).
This separated ossification center, called ossiculum terminale, appears at the age of three years and fuses by twelve years. These synchondroses between axis and base of odontoid are potentially weak areas susceptible to traumatic disruption and in many manuscripts describe physeal separation. This abnormality frequently leads to atlantoaxial dislocation (AAD). Most of these dislocations are reducible and in a minority, atlantoaxial dislocation might be missed and gradually become irreducible (IAAD) and this form is a considerable challenge for the spine surgeons (2).

The current report is on a rare case with os odontoideum displaced with a minor trauma and referred to the center with severe myelopathy.

\section{Case Presentation}

The ethical board approved reporting the case of a sixteen-year-old boy who fell off the bicycle eight months ago. He had been visited in the emergency department of a local hospital and after physical examination discharged; then two weeks before admission in the center he fell off the bicycle again and was hospitalized due to neck pain and torticollis and equilibrium impairment. 
In the past months he had several episodes of spontaneous falling down with upper and lower limb tingling.

The patient had not experienced unconsciousness and the neurological examination revealed that finger to nose test was impaired and he had positive Romberg test. Deep tendon reflexes were exaggerated.

Initial anteroposterior and lateral radiographs of cervical spine revealed a non-anatomic odontoid process (Figure 1).

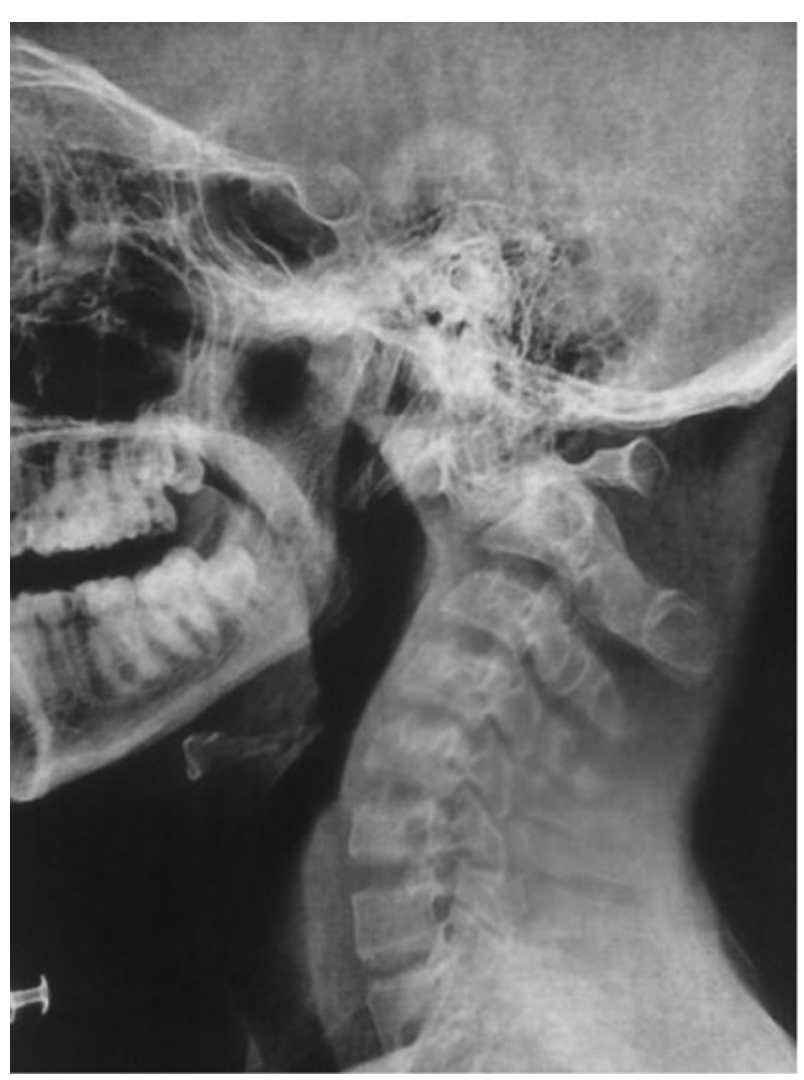

Figure 1. Initial Lateral Radiographs of Cervical Spine Revealed a Non-Anatomic Odontoid Process

Computed tomography (CT) scan demonstrated displaced os odontoideum with the space available for cord (SAC) less than $10 \mathrm{~mm}$ (Figure 2) and myelomalacia was observed in magnetic resonance imaging (MRI) (Figure 3). In the CT scan, there was no contact between odontoid process and body of axis(C2) in sagittal cut and it was displaced to anterior completely. The border of fracture site was sclerotic and not fresh.

According to these imaging and the clinical presentations, displaced os osontoideum was diagnosed, halotraction was applied, skeletal traction was started and the patient was checked clinically and through radiography.

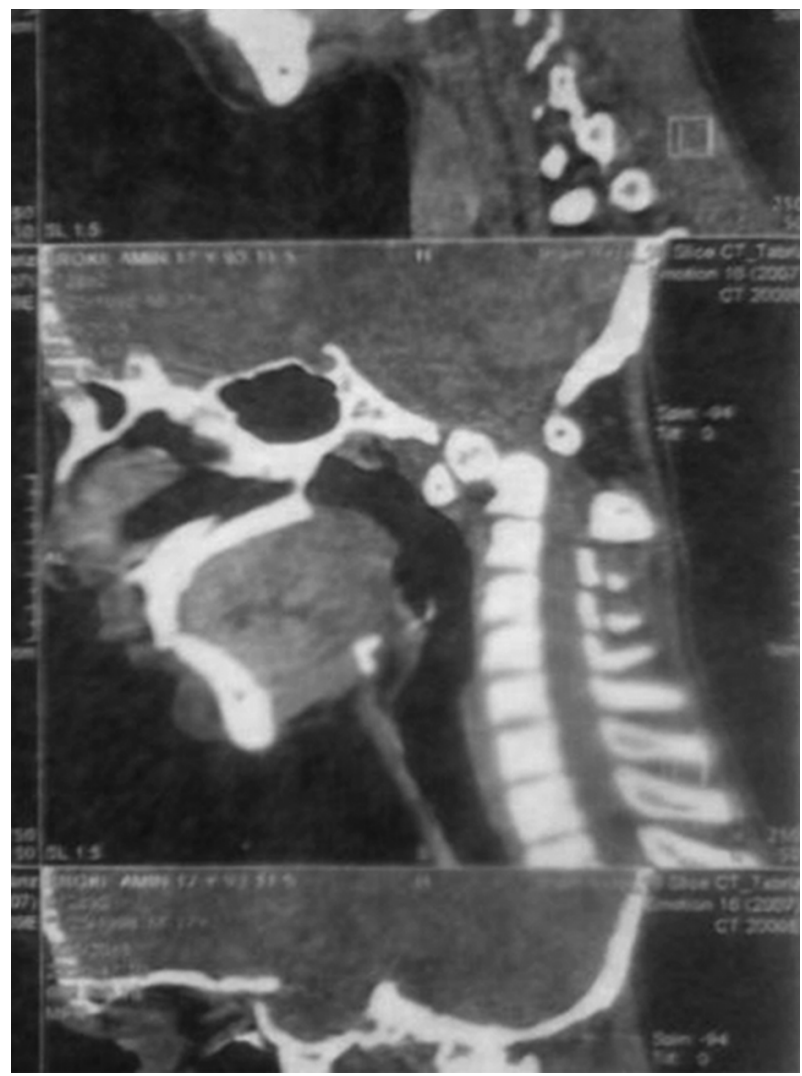

Figure 2. CT Scan Showed a Displaced Os Odontoideum With Minimal Space Available for Cord $(<10 \mathrm{~mm})$

No reduction was observed after three days of incremental skeletal traction and the patient was scheduled for anterior decompression with transoral approach. He was transferred to the operation room with halo ring and then after general anesthesia authors passed a Nelaton catheter into a nostril, and sutured it to the uvula. Traction was applied to the catheters to stretch the uvula and soft palate out of the surgical field, then a McGarver retractor was inserted into the mouth to open and retract oropharynx prepared with povidone-iodine (Betadine) and then the posterior pharyngeal wall was infiltrated with epinephrine solution (1;500000 concentration) to prevent excessive bleeding. After palpation of the anterior ring of $\mathrm{C} 1$ under the posterior pharynx, the incision was done in the wall of the posterior pharynx from the superior margin of $\mathrm{C} 1$ to the top of C3.

Then with high speed burr the anterior ring of $\mathrm{C} 1$ was removed, displaced odontoid was resected, the cord was decompressed and the patient was transferred to intensive care unit (ICU) with halo-traction (Figure 4). In early postoperative radiography, displaced odontoid was not re- 


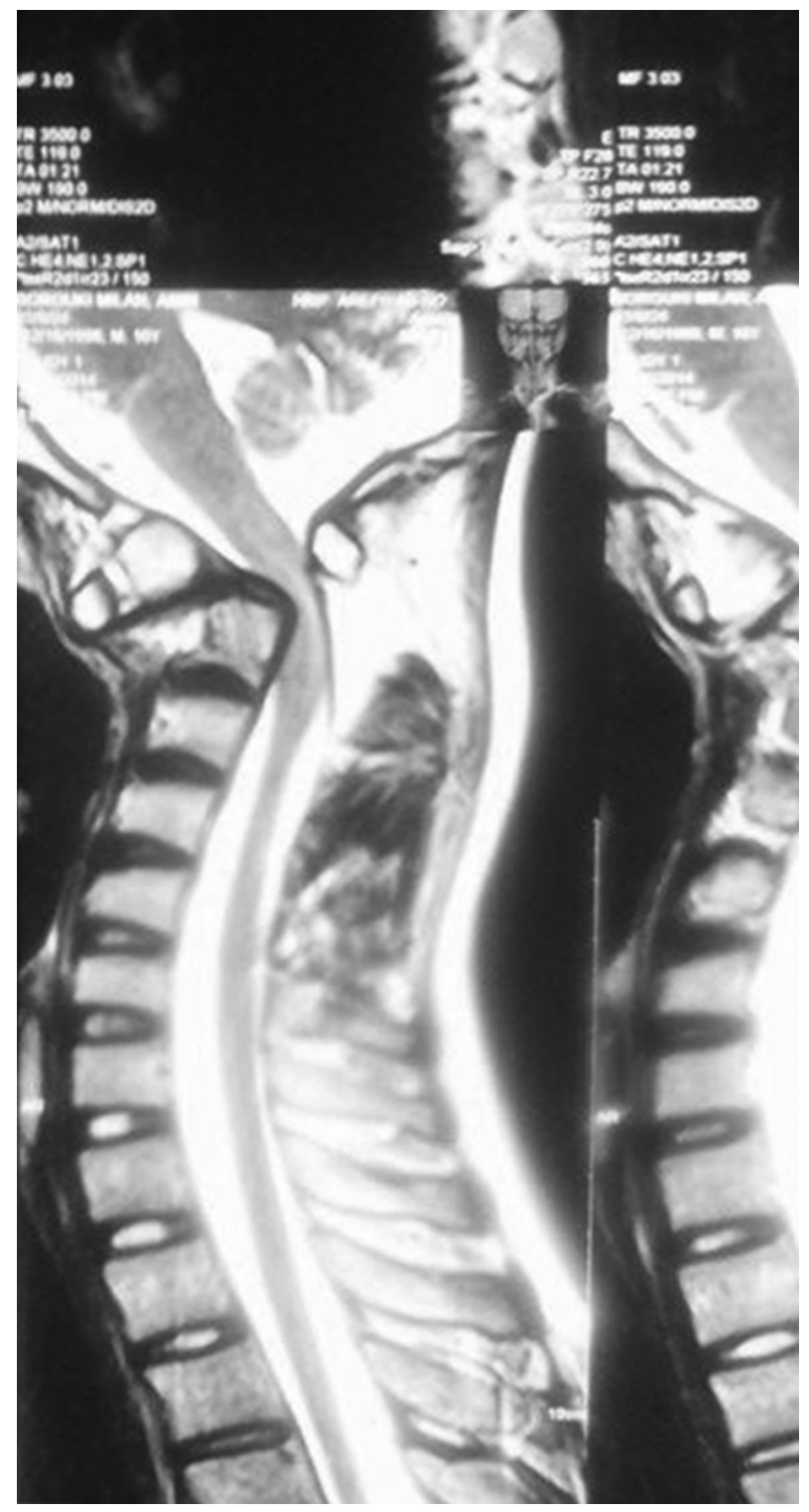

Figure 3. MRI Showed Severe Cord Compression With Myelomalacia

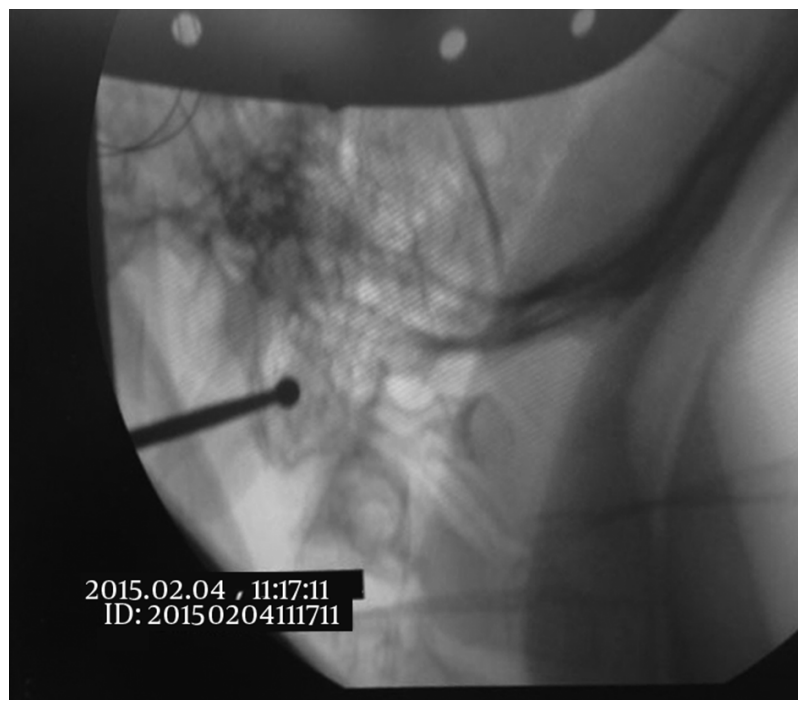

Figure 4. Anterior Decompression With Power Burr (Intra-Operative Fluoroscopic Image)

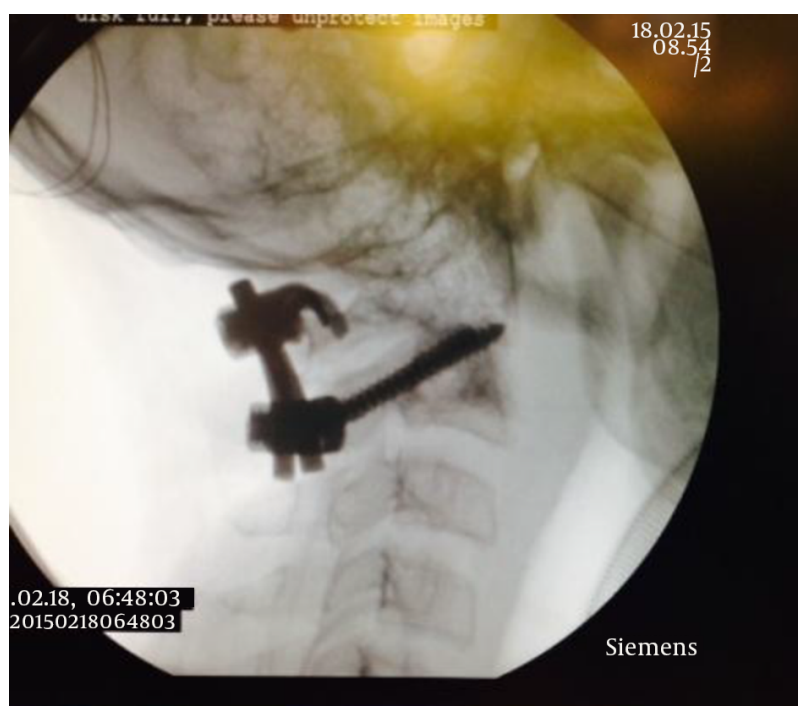

Figure 5. Final Stabilization With Bilateral C1 Hook and C2 Pedicular Screws (IntraOperative Image)

\section{Discussion}

The recent developments on advanced imaging techniques (high-resolution CT scan and MRI) allow more accurate examination of the upper cervical spine in children. However, whether the origin of an os odontoideum is congenital or acquired (posttraumatic) remains controversial (5-13). Fielding et al. reported that nine patients subsequently developed os odontoideum despite 

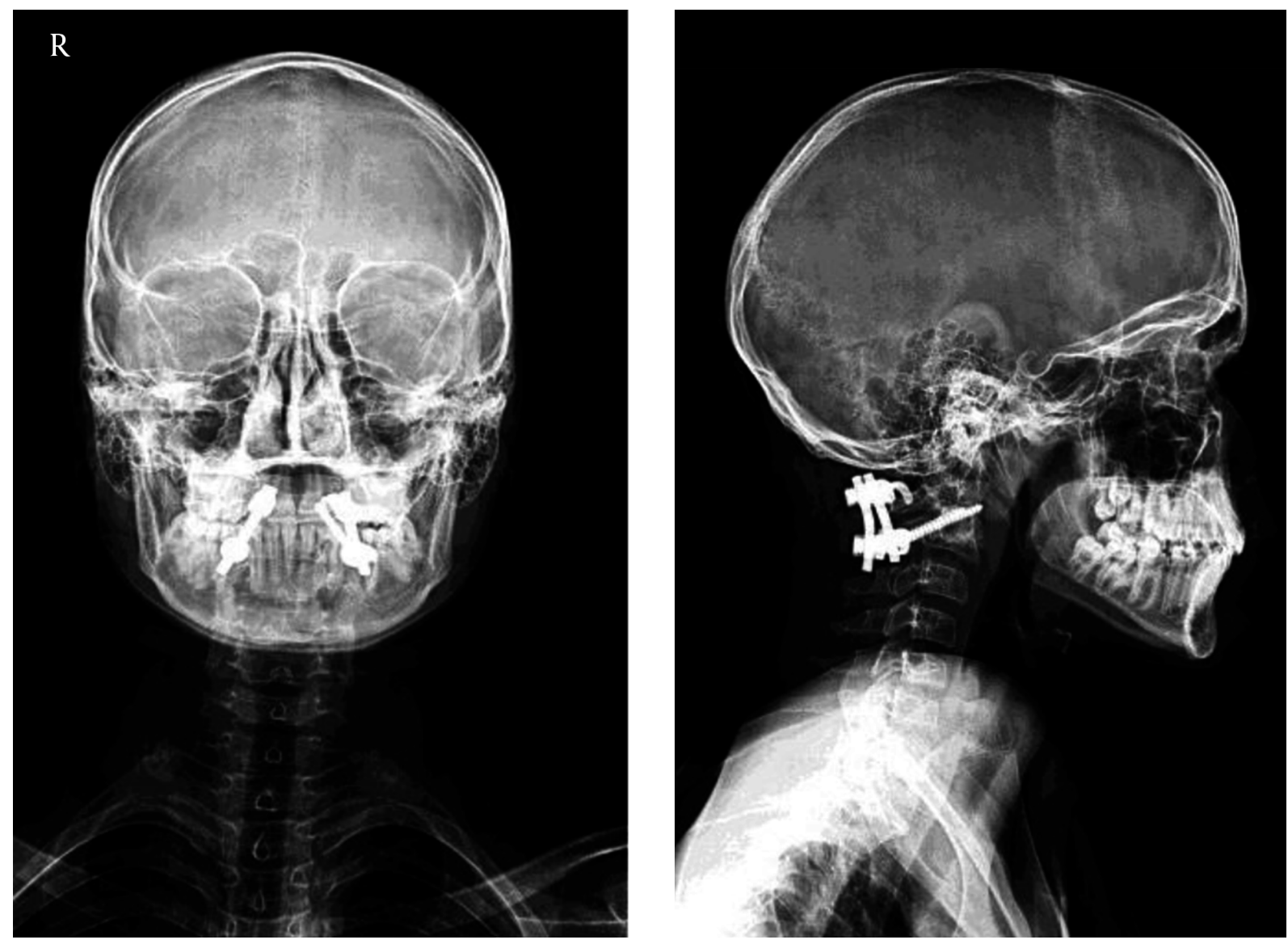

Figure 6. AP and Lateral Radiography After Three Months

normal post traumatic X-rays (5). The evidence suggests that a missed fracture and then subsequent odontoid osteonecrosis might be the cause of os odontoideum. The important point in congenital anomalies of the odontoid is an already abnormal C1-C2 instability that can be subluxated or dislocated with minor trauma and cause permanent neurologic deficit or even death (13). Patients with localized symptoms such as neck pain usually improve with conservative treatment (traction or immobilization) (1). The common indications of surgical treatment are 1) neurologic deficit (even transient), 2) anterior or posterior C1C2 instability more than $5 \mathrm{~mm}, 3$ ) progressive C1-C2 instability and 4) persistent local symptoms (neck pain, torticollis, etc.) not relieved by conservative treatment (1). Robson reported the case of a 22-year-old female referred to the emergency department, after a martial arts exercise, with transient weakness and numbness in all extremities referred to the neurosurgery division for atlanto-axial fusion (14). Numerous surgical techniques are described for this rare anatomic disorder. Reilly and Choit described their practice with posterior $\mathrm{C1}-\mathrm{C} 2$ transarticular screw fixation for pediatric C1-C2 instability (15). Brecknell and Malham reported three cases of os odontoideum treated surgically with posterior C1-C2 fusion with polyaxial screw/rod fixation (16). A few reports on out surgical management of patients with irreducible atlantoaxial dislocation (IAAD) are available.

Ai et al. described a one-stage transoral technique for IAAD. In this technique after resection of articular capsule and scar tissues inside the atlanto-axial facet, reduction and fixation was achieved with transoral atlantoaxial reduction plate (TARP). This plate was fixed by bilateral anterior $\mathrm{C} 1$ lateral mass and C2 pedicular screws (17). Another single stage method in IAAD was reported by Chang-Wei et al. that is posterior rotating rod. In this method, $\mathrm{C1}-\mathrm{C} 3$ lateral mass and $\mathrm{C} 2$ pars screws are inserted, then a curved rod with its convex side posteriorly are placed and nuts are tightened loosely. Then both rods are simultaneously rotated till the rod is in lordotic position (18).

Yin et al. described their experience in reduction of 
IAAD by single stage posterior facet release and fusion with C1 lateral mass and C2 pedicular screws (19).

Generally, in patients with no neurologic deficit, in situ posterior fusion can be performed with no significant risk, but in patients with neurologic deficit the first step is skeletal traction and after reduction, atlantoaxial fusion should be placed. Sometimes skeletal traction fail and reduction is impossible, under such circumstances decompression or release can be done anteriorly or posteriorly (1).

Authors approached the patient urgently, because of significant neurologic deficit, planned a 2-stage procedure; anterior release and odontoidectomy and halotraction followed by posterior C1-C2 fusion with bilateral $\mathrm{C} 1$ hooks and $\mathrm{C} 2$ pedicular screws. A week after the final surgery the patient was discharged in good general condition and nearly normal walking ability.

\section{Footnote}

Authors' Contribution: Study design: Farshad Nikouei; manuscript preparation and revision: Farshad Nikouei, Khodakarm Rastegar, Saeed Sabbaghan and Ali Andalib; study supervision: Farshad Nikouei.

\section{References}

1. Warner WC. Pediatric cervical spine. In: Canale ST, Beaty JH, editors. Campbell's operative orthopaedics. 12 ed. Philadelphia: ElsevirMosby; 2013. pp. 1653-60.

2. Wada E, Matsuoka T, Kawai H. Os odontoideum as a consequence of a posttraumatic displaced ossiculum terminale. A case report.J Bone Joint Surg Am. 2009;91(7):1750-4. doi: 10.2106/JBJS.H.01182. [PubMed: 19571099].

3. Dempster AG, Heap SW. Fatal high cervical spinal cord injury in an automobile accident complicating os odontoideum. Am J Forensic Med Pathol. 1990;11(3):252-6. [PubMed: 2220713].

4. Chutkan NB, King AG, Harris MB. Odontoid Fractures: Evaluation and Management. J Am Acad Orthop Surg. 1997;5(4):199-204. [PubMed: 10797222].
5. Fielding JW. Disappearance of the Central Portion of the Odontoid Process: A Case Report.J Bone Joint Surg Am. 1965;47:1228-30. [PubMed: 14337782]

6. Freiberger RH, Wilson PD, Nicholas JA. Acquired Absence of the Odontoid Process: A Case Report. J Bone Joint Surg Am. 1965;47:1231-6. [PubMed: 14337783].

7. Fielding JW, Griffin PP. Os odontoideum: an acquired lesion. J Bone Joint Surg Am. 1974;56(1):187-90. [PubMed: 4812163].

8. Hawkins RJ, Fielding JW, Thompson WJ. Os odontoideum: congenital or acquired. A case report. J Bone Joint Surg Am. 1976;58(3):413-4. [PubMed: 1262377].

9. Ricciardi JE, Kaufer H, Louis DS. Acquired os odontoideum following acute ligament injury. Report of a case. J Bone Joint Surg Am. 1976;58(3):410-2. [PubMed: 1262376].

10. Hukuda S, Ota H, Okabe N, Tazima K. Traumatic atlantoaxial dislocation causing os odontoideum in infants. Spine (Phila Pa 1976). 1980;5(3):207-10. [PubMed: 7394658].

11. Wollin DG. The Os Odontoideum. Separate Odontoid Process. J Bone Joint Surg Am. 1963;45:1459-71. [PubMed: 14069784].

12. Schatzker J, Rorabeck CH, Waddell JP. Fractures of the dens (odontoid process). An analysis of thirty-seven cases. J Bone Joint Surg Br. 1971;53(3):392-405. [PubMed: 5562366].

13. Greenberg AD. Atlanto-axial dislocations. Brain. 1968;91(4):655-84. [PubMed: 5704829].

14. Robson KA. Os odontoideum: rare cervical lesion. West J Emerg Med. 2011;12(4):520-2. doi: 10.5811/westjem.2011.4.2029. [PubMed: 22224150].

15. Reilly CW, Choit RL. Transarticular screws in the management of C1-C2 instability in children. J Pediatr Orthop. 2006;26(5):582-8. doi: 10.1097/01.bpo.0000230337.26652.55. [PubMed: 16932095].

16. Brecknell JE, Malham GM. Os odontoideum: report of three cases. J Clin Neurosci. 2008;15(3):295-301. doi: 10.1016/j.jocn.2006.07.022. [PubMed: 18178439].

17. Ai FZ, Yin QS, Xu DC, Xia H, Wu ZH, Mai XH. Transoral atlantoaxial reduction plate internal fixation with transoral transpedicular or articular mass screw of $\mathrm{c} 2$ for the treatment of irreducible atlantoaxial dislocation: two case reports. Spine (Phila Pa 1976). 2011;36(8):E556-62. doi: 10.1097/BRS.0b013e3181f57191. [PubMed: 21242871].

18. Chang-Wei L, Wei L, Zhen-Sheng M, Yan-Wu L, Long B, Nan Z. Posterior rotating rod reduction strategy for irreducible atlantoaxial subluxations with congenital odontoid aplasia. Spine (Phila Pa 1976). 2010;35(23):2064-70. doi: 10.1097/BRS.0b013e3181ce1758. [PubMed: 20938396].

19. Yin YH, Qiao GY, Yu XG, Tong HY, Zhang YZ. Posterior realignment of irreducible atlantoaxial dislocation with C1-C2 screw and rod system: a technique of direct reduction and fixation. Spine J. 2013;13(12):186471. doi: 10.1016/j.spinee.2013.08.014. [PubMed: 24183463]. 